\title{
Acetylator phenotype in spontaneous SLE and rheumatoid arthritis
}

\author{
D. H. LAWSON, D. A. HENRY, J. LOWE, P. REAVEY, \\ J. A. N. RENNIE, AND A. SOLOMON
}

From the Medical and Laboratory Divisions, Glasgow Royal Infirmary

SUMMARY Acetylator phenotype was determined in 22 patients with spontaneous systemic lupus erythematosus and the proportion of 'slow' acetylators compared with that obtained in a group of patients with rheumatoid arthritis and a group of healthy controls. $73 \%$ of the SLE group were designated 'slow' compared with $72 \%$ of the rheumatoid group and $64 \%$ of the control group. These differences were not significant.

A number of primary amine drugs such as dapsone, isoniazid, hydrallazine, procainamide, and many of the sulphonamides are acetylated by the $\mathrm{N}$-acetyltransferase enzyme at rates which are bimodally distributed in man (Evans et al., 1960; Evans and White, 1964; Gelbert et al., 1971; Zacest and Koch-Weser, 1972; Karlsson et al., 1975). Several of these drugs have been implicated in the development of systemic lupus erythematosus (SLE) (Alarcon-Segovia, 1976). This has been reported more frequently in slow acetylators of the suspected drug (Lunde et al., 1977), a fact which could indicate either a genetic predisposition of such individuals or result from a direct effect of the parent drug which becomes inoperative once the acetylated derivative is formed. If the former is the explanation, it is possible that there would be an increased prevalence of slow acetylators among patients with spontaneously occurring SLE. There is already some evidence in support of this hypothesis, since Reidenberg and Martin (1974) reported that 11 of 14 patients with spontaneous SLE were slow acetylators as compared with an expected frequency of $50 \%$ in the local population.

The present report describes an investigation into the distribution of the acetylator phenotype in patients with spontaneous SLE, comparing them with rheumatoid arthritics and normal persons.

\section{Patients and methods}

In all instances acetylator phenotype was determined by the method of Schröder (1972). Patients were

Accepted for publication 21 April 1978

Correspondence to Dr D. A. Henry, Department of Therapeutics, City Hospital, Hucknall Road, Nottingham. given $1 \mathrm{~g}$ sulphadimidine orally, and their urine was collected for 1 hour between 5 and 6 hours after ingestion of the drug. Urine samples were analysed for free and acetylated sulphadimidine by the method described by Schröder. Results were expressed as a percentage of the acetylated drug in the urine. Slow acetylators were defined as having less than $70 \%$ acetylated sulphadimidine in the urine.

A total of 72 subjects were tested: 22 with spontaneous SLE as defined by the American Rheumatism Association criteria (Cohen et al., 1971), 25 with either classical or definite rheumatoid arthritis (Ropes et al., 1959), and 25 normal controls. All were attending hospital either as outpatients or as staff and were on normal diets. At the time of the study no patient was taking a drug which was metabolised by acetylation. All patients had normal renal function as shown by normal blood urea and serum creatinine concentrations at the time of the test. The mean ages, sex distribution, and blood urea concentrations in these subjects are shown in Table 1.

\section{Results}

The distribution of acetylator capacity in the 3 groups of subjects studied is shown in Fig. 1. Of the

Table 1 Characteristics of patients studied

\begin{tabular}{llll}
\hline & $\begin{array}{l}\text { Spontaneous } \\
\text { SLF }\end{array}$ & $\begin{array}{l}\text { Rheumatoid } \\
\text { arthritis }\end{array}$ & $\begin{array}{l}\text { Normal } \\
\text { subjects }\end{array}$ \\
\hline Number & 22 & 25 & 25 \\
Number of males & 6 & 9 & 10 \\
Age $( \pm S D)$ years & $36 \pm 10$ & $61 \pm 14 \cdot 2$ & $25 \pm 5 \cdot 1$ \\
Blood urea mmol/1 & $5 \cdot 2 \pm 1 \cdot 2$ & $6 \cdot 2 \pm 2 \cdot 1$ & $4 \cdot 4 \pm 0 \cdot 9$ \\
\hline
\end{tabular}




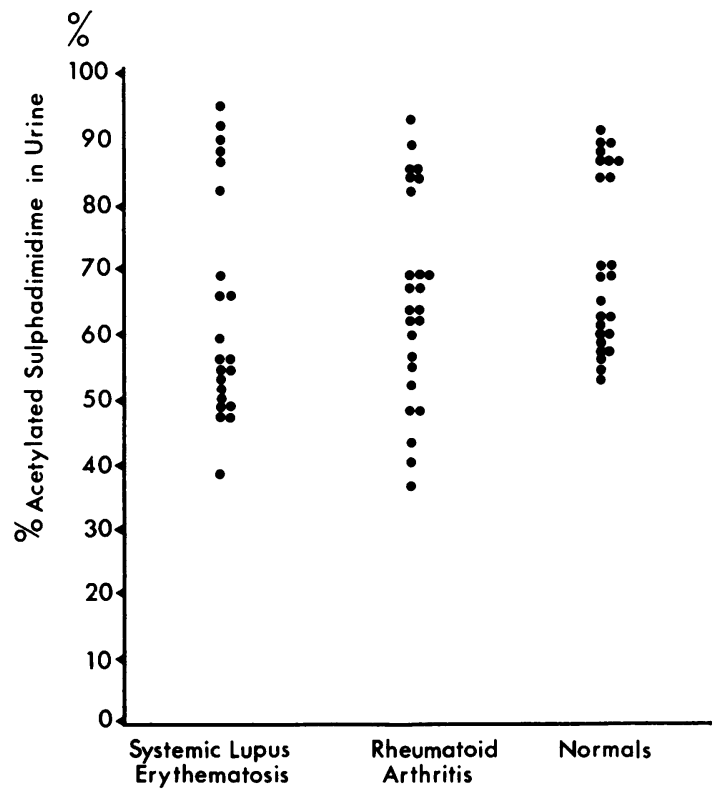

Fig. 1 Comparison of the proportion of acetylated sulphadimidine in patients with spontaneous SLE, rheumatoid arthritis, and healthy volunteers

22 patients with SLE 6 were fast acetylators (27\%) as compared with 7 of the 25 rheumatoid arthritics $(28 \%)$ and 9 of the 25 normal subjects (36\%). These differences could readily have arisen by chance $\left(\mathrm{X}^{2}(\mathrm{DF}=2)=0 \cdot 54, \mathrm{P}>0 \cdot 1\right)$. The mean proportion of acetylated sulphadimidine was $63 \cdot 7 \%(\mathrm{SD}=17 \cdot 4)$ in those with SLE, $65 \cdot 3 \%(\mathrm{SD}=16 \cdot 0)$ in those with $\mathrm{RA}$, and $70 \cdot 7 \%(\mathrm{SD}=13.6)$ in normal volunteers.

\section{Discussion}

This study does not support the finding of Reidenberg and Martin (1974) that there is an excess of phenotypically slow acetylators among patients with spontaneous SLE. There were no significant differences in the prevalence of slow acetylators of sulphadimidine in a large group of patients with spontaneous SLE, a group with rheumatoid arthritis, and a group of normal volunteers. The test used was simple, reliable, and reproducible (Schröder, 1972), and easy to perform on large numbers of patients. The only 2 sources of error with this technique result from using it in patients with impaired renal function or in patients who are coincidentally receiving significant amounts of other acetylated drugs, for example, procainamide (Campbell et al., 1976). Neither of these 2 situations pertained in the present study. Sulphadimidine was used as the test drug, since its acetylation rates have been shown to correlate well with those of othere polymorphically acetylated drugs (Lunde et al. 1977).

More recently Larsson et al. (1977) studied? acetylation capacity using isoniazid half-times in plasma in a group of 15 patients with SLE who were not taking concurrent drug therapy. Only 2 of these patients were rapid acetylators. However, 7 ofis them had chronic renal failure with glomerularo filtration rates between 17 and $41 \mathrm{ml} / \mathrm{min}-\mathrm{a}$ factorwhich could introduce difficulties in measuring acetylator capacity. A similar problem exists in the data presented by Reidenberg and Martin (1974)? Moreover, Molin et al. (1977) showed that, al $-\infty$ though the distribution of slow and fast acetylatorsiv of sulphapyridine was 50:50 in Sweden when study ing normal individuals, a distinct bias towards slow acetylators was apparent when patients admitted to ? hospital for cardiac or renal diseases were studied. Thus it is not clear from these observations whethero the reported trend towards fewer than normal fast. acetylators in patients with spontaneous SLE is a $\overrightarrow{0}$ reflection of the disease itself or of extraneous 6 factors associated with attendance at hospital. The present study compares the acetylator capacity of outpatients with spontaneous SLE with that of $2 \frac{\bar{O}}{2}$ other groups, one of which had rheumatoid arthritiso and one of which was normal. It fails to confirm that acetylator phenotype is a useful marker for the spontaneous form of SLE.

\section{References}

Alarcon-Segovia, D. (1976). Drug-induced antinuclear antibodies and lupus syndrome. Drugs, 12, 69-77.

Campbell, W., Tilstone, W. J., Lawson, D. H., Hutton, I.을 and Lawrie, T. D. V. (1976). Acetylator phenotype and the clinical pharmacology of slow-release procainamide British Journal of Clinical Pharmacology, 3, 1023-1026.

Cohen, A. S., Reynolds, W. E., Franklin, E. C., Kulka, J. P., Ropes, M. W., Shulman, L. E., and Wallace, S. L.O (1971). Preliminary criteria for the classification of systemic lupus erythematosus. Bulletin on Rheumatio Diseases, 21, 643-648.

Evans, D. A. P., Manley, K. A., and McKusick, V. A. (1960) N Genetic control of isoniazid metabolism in man. British? Medical Journal, 2, 485-491.

Evans, D. A. P., and White, T. A. (1964), Human acetylation polymorphism. Journal of Laboratory and Clinica Medicine, 63, 394-403.

Gelbert, R., Peters, J. H., Gordon, G. R., Glazko, A. J and Levy, I. (1971). The polymorphic acetylation of dapsone in man. Clinical Pharmacology and Therapeutics 12, 226-238.

Karlsson, E., Molin, L., Morlander, B., and Sjoquist, F⿱一兀 (1975). Acetylation of procainamide in man studied with a new gas chromatographic method. British Journal of Clinical Pharmacology, 1, 467-475.

Larsson, R., Karlsson, E., and Molin, L. (1977). Spon尺 taneous systemic lupus erythematosus and acetylato르 phenotype. Acta Medica Scandinavica, 201, 223-228. 
Lunde, P. K. M., Frislid, K., and Hansteen, V. (1977) Disease and acetylation polymorphism. Clinical Pharmacokinetics, 2, 182-197.

Molin, L., Larsson, R., and Karlsson, E. (1977). Evaluation of the sulphapyridine acetylator phenotype test in healthy subjects and in patients with cardiac and renal diseases. Acta Medica Scandinavica, 201, 217.

Reidenberg, M. M., and Martin, J. H. (1974). Acetylator phenotype of patients with systemic lumps erythematosus. Drug Metabolism and Disposition, 2, 71-73.
Ropes, M. W., Bennett, C. A., Cobb, S., Jacox, R., and Jessar, R. A. (1959). 1958 revision of diagnostic criteria for rheumatoid arthritis. Annals of the Rheumatic Diseases, 19, 49.

Schröder, H. (1972). Simplified method for determining acetylator phenotype. British Medical Journal, 3, 506-507.

Zacest, R., and Koch-Weser, J. (1972). Relation of hydrallazine plasma concentration to dosage and hypotensive action. Clinical Pharmacology and Therapeutics, 13, 420-425. 